\title{
Optical and structural study of thin film of polyazomethine with triphenylamine unit prepared via spin-coating method
}

\author{
M. Palewicz • A. Iwan · J. Doskocz $\cdot$ W. Strek • \\ D. Sek • B. Kaczmarczyk • B. Mazurek
}

Received: 1 February 2010/Revised: 11 May 2010/Accepted: 23 May 2010/

Published online: 8 June 2010

(C) The Author(s) 2010. This article is published with open access at Springerlink.com

\begin{abstract}
A conjugated aromatic polyazomethine (PAZ) with triphenylamine (TPA) unit in the main chain was obtained by high temperature solution polycondensation of diformyltriphenylamine with $o$-dianisidine (Fast blue B). A major feature of the PAZ containing TPA unit in the main chain is their complete solubility in comparison with PAZ obtained from terephthaldicarboxaldehyde and $o$-dianisidine (abbreviated hereinafter as PAZ1). Both polymers were analyzed by thermogravimetric analysis and FTIR spectroscopy. UV-vis absorption, X-ray diffraction (X-ray) and Atomic Force Microscopy (AFM) techniques were used to probe the optical properties and morphology of the thin films of the PAZ prepared by spin-coating technique on the glass and quartz substrate. Thickness of the PAZ thin layer on the glass and quartz substrate were determined by ellipsometer at the range $150-220 \mathrm{~nm}$. The optical band gap value $\left(E_{\mathrm{g}}\right)$ of the thin films PAZ was detected at $2.45 \mathrm{eV}$. The current-voltage $(I-V)$ characteristic was measured to confirm semiconductor nature of the PAZ.
\end{abstract}

\footnotetext{
M. Palewicz

Institute of Electrical Engineering Fundamentals, Wroclaw University of Technology, 27 Wybrzeze Wyspianskiego Street, 50-370 Wroclaw, Poland

M. Palewicz $(\varangle) \cdot$ A. Iwan · B. Mazurek

Electrotechnical Institute Division of Electrotechnology and Materials Science,

M. Sklodowskiej-Curie 55/61, 50-369 Wroclaw, Poland

e-mail: m.palewicz@iel.wroc.pl

J. Doskocz · W. Strek

Institute of Low Temperature and Structure Research, Polish Academy of Sciences,

Okolna 2, 50-422, P.O. Box 1410, 50-950 Wroclaw 2, Poland

D. Sek · B. Kaczmarczyk

Centre of Polymer and Carbon Materials, Polish Academy of Sciences,

34 M. Sklodowska-Curie Street, 41-819 Zabrze, Poland
} 
Keywords Polyzomethines - Spin-coating method - Semiconducting polymers . Triphenylamine

\section{Introduction}

Investigations of organic materials for photovoltaic devices were begun because of increasing demand of logging energy. First, practical tape of solar cells was connected with mono-crystal material like silicon, which had a single band gap and efficiency coefficient about six percentage [1]. Nowadays thin crystals multilayer structure with quantum wells and dots were investigated to diffuse energetic application and that generation of solar cells were denominated as third generation [2]. However, manufacturing of such devices were still expensive and had negative effect on natural environment. For these reasons an organic materials for photovoltaic devices are investigated. Use of the organic materials was supposed to be very promising in photovoltaic devices because of economic reasons and high demand of products [1]. One of the first solar cells which could be considered as organic origin was characterized by Tang [3]. At thin film, two-layer organic photovoltaic cell was fabricated from copper phthalocyanine and a perylene tetracarboxylic derivative [3]. However, no product of conducted research was used in commercial application.

Among them, much attention was paid to triphenylamine (TPA) derivatives because they were promising candidates for photo- and electro-luminescence materials. TPA is a unique molecule possessing useful function such as redoxactivity, fluorescence and transport of positive charge centres via the radical cation species. Being efficient hole conductors, TPA is commonly used us photoconductors. Introduction of azomethine moieties $(\mathrm{HC}=\mathrm{N})$ in TPA may lead to new functional materials based on the synergistic effect of both of them. Additionally, polyazomethines (PAZs) are known to display interesting thermal, mechanical, electrical, optical and fibre-forming properties and they are promising materials in optoelectronic and photonic applications [4]. Materials which were taken advantage of the TPA derivatives in solar cells basing on dyes were described in [5]. Authors were approached a correlation between chemical structure of used compounds and physical properties of dye-sensitized solar cells (DSSC). To ascertainment at usefulness of dyes, which contained TPA in the main chain, optical quality, energy levels and fundamental processes in DSSC were described. Obtained by Mishra et al. [5] results of efficiency of prototype solar cells, absorption range and influence of texture on dyes containing TPA moieties induced possibility to exploit such devices in scatter energetic in near future [5].

This paper reported the first example of the used of a spin-coating method for investigation optical and structural properties of the layer on the glass and quartz substrate composed from PAZ with TPA unit in the main chain. PAZ was studied by UV-vis, X-ray diffraction (X-ray), Atomic Force Microscopy (AFM) and currentvoltage $(I-V)$ characteristics.

To the best of our knowledge it is the first paper where optical and structural methods such as UV-vis, AFM, X-ray and current-voltage $(I-V)$ of the PAZ with 
TPA prepared by spin-coating technique were investigated. Our study demonstrates that PAZ with TPA in the main chain can be used as one of the layers in organic solar cells.

\section{Experimental}

\section{Materials}

$o$-Dianisidine (3,3'-dimethoxybenzidine, Fast blue B) (Aldrich), terephthaldicarboxaldehyde (Aldrich), hexamethylphosphoramide (HMPA) (Aldrich) and $N, N$ dimethylformamide (DMF) were used as received. 4,4'-Diformyltriphenylamine (4,4'-(phenylimino)bisbenzaldehyde) was prepared by Vilsmeier reaction according to the method described in the literature $[6,7]$.

\section{Synthesis of PAZ}

The aromatic PAZ containing the TPA in the main chain, namely the fully conjugated PAZ (see Fig. 1a) was prepared using the method described previously [6]. Macromolecular parameters, spectroscopic and thermal data of the PAZ prepared are listed below [6]:

PAZ. Yield: 63\%. Anal. Calcd for $\mathrm{C}_{34} \mathrm{H}_{28} \mathrm{~N}_{3} \mathrm{O}_{2}$ (510.613): C, 80.16; H, 5.30; N, 8.25. Found: C, 79.11; H, 5.40; N, 8.19. FTIR spectrum (KBr pellet): 3060 and 3033 $(v \mathrm{CH}), 2998,2933,2870$ and $2832\left(v \mathrm{CH}_{3}\right), 1691(v \mathrm{C}=\mathrm{O}), 1623(v \mathrm{C}=\mathrm{N}), 1588$, 1559, 1505, 1489, 1463, 1428 and $1417(v \mathrm{Ph}), 1481$ and $1393\left(\delta \mathrm{CH}_{3}\right), 1318$ $(\delta \mathrm{CH}), 1285(\omega \mathrm{CH}), 1260 \mathrm{sh}(\delta \mathrm{CH} / v \mathrm{Ph}-\mathrm{N}), 1243,1195(v \mathrm{Ph}-\mathrm{N}=), 1168(\delta \mathrm{CH})$, $1129(\delta \mathrm{CH} / v \mathrm{CO}), 1029\left(v \mathrm{CO} / \rho^{\prime} \mathrm{CH}_{3}\right), 875,880,831(\gamma \mathrm{CH}), 754$ and $696(\gamma \mathrm{Ph})$.

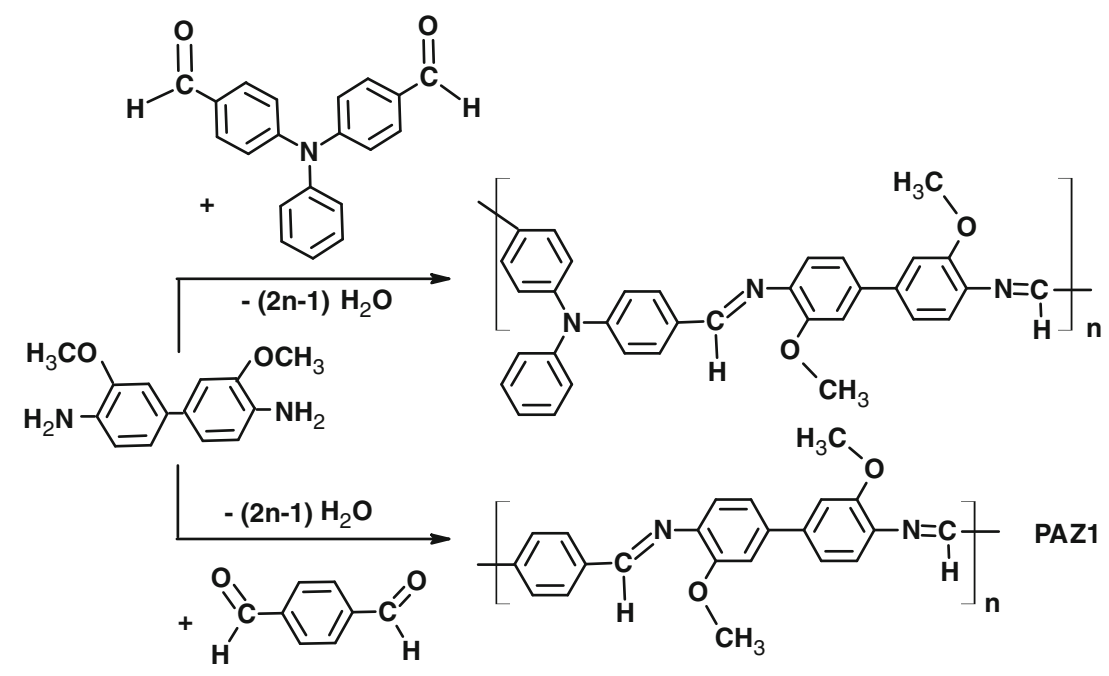

Fig. 1 Synthetic route and chemical structures of the synthesized polyazomethines 
${ }^{1} \mathrm{H}$ NMR $\left(\mathrm{CDCl}_{3}, \mathrm{ppm}\right): 8.47(\mathrm{HC}=\mathrm{N}) ;{ }^{13} \mathrm{C} \mathrm{NMR}\left(\mathrm{CDCl}_{3}, \mathrm{ppm}\right) 160.15(\mathrm{HC}=\mathrm{N})$ $(v$-stretching vibrations, $\delta$-in plane deformation, $\gamma$-out-of-plane deformation, $\mathrm{Ph}$ - phenyl). UV-vis recorded in chloroform $\lambda_{\max }$ at $413 \mathrm{~nm}, E_{\mathrm{g}}$ calculated from the absorption spectra of the polymer film cast from solution $2.50 \mathrm{eV}, E_{\mathrm{g}}$ determined from electrochemical experiment in dichloromethane solution $2.65 \mathrm{eV}$, $E_{\mathrm{g}}$ calculated from the absorption spectra of the polymer in dichloromethane solution $2.69 \mathrm{eV}$, Photoluminescence (PL) in chloroform $\lambda_{\max }$ at $480 \mathrm{~nm}$ (excitation $400 \mathrm{~nm}$ ), FWHM $42 \mathrm{~nm}$, Stokes shift $3380 \mathrm{~cm}^{-1} . T_{\mathrm{g}}$, DSC: $178^{\circ} \mathrm{C}$.

\section{Synthesis of PAZ1}

The PAZ1 was prepared by polycondensation method in DMA solution by adopting the literature procedures reported for PAZs [4]. Yield: 80\%. Anal. Calcd for $\mathrm{C}_{22} \mathrm{H}_{19} \mathrm{NO}_{2}$ (343.398): C, 76.95; H, 5.58; N, 8.16. Found: C, 76.81; H, 5.45; N, 8.19. FTIR spectrum (KBr pellet): 3060 and $3033(v \mathrm{CH}), 3004=\mathrm{C}-\mathrm{H}, 2957,2935$, 2871 and $2832\left(v \mathrm{CH}_{3}\right), 1699(v \mathrm{C}=\mathrm{O}), 1629(v \mathrm{C}=\mathrm{N}), 1588,15641556,1524,1504$, 1461, 1441, 1418 and $1305(v \mathrm{Ph}), 1486$ and $1361\left(\delta \mathrm{CH}_{3}\right), 1242(\delta \mathrm{CH}), 1194$ $(v \mathrm{Ph}-\mathrm{N}=), 1176(\delta \mathrm{CH}), 1128(\delta \mathrm{CH} / v \mathrm{CO}), 1026\left(v \mathrm{CO} / \rho^{\prime} \mathrm{CH}_{3}\right), 976,881,832$ and $817(\gamma \mathrm{CH}), 770(v \mathrm{Ph})$. ( $v$-stretching vibrations, $\delta$-in plane deformation, $\gamma$-out-of-plane deformation, $\mathrm{Ph}$-phenyl): $T_{\mathrm{g}}$, DSC: $258^{\circ} \mathrm{C}$.

\section{Characterisation techniques}

Infrared spectra were acquired on a DIGILAB FTS-40A Fourier transform infrared spectrometer in the range of $3500-400 \mathrm{~cm}^{-1}$ at a resolution of $2 \mathrm{~cm}^{-1}$ and for an accumulated 32 scans. Sample was analyzed as pellet in potassium bromide. Twobeam spectrophotometer Cary 5000 was used to measure optical properties of the thin PAZ layer. The absorption $(A)$, transmission $(T)$ and reflectance $(R)$ measurements were performed at room temperature. The surface morphology investigations of the PAZ prepared via spin-coating technique on the glass and quartz were performed in air using a Atomic Force Microscope (AFM-Wroclaw University of Technology) in the contact mode. X-ray diffraction patterns were recorded using film samples on a Pulveraceous diffractometer Dron-2. Co radiation filtrated by $\mathrm{Fe}$ was applied. The thermogravimetric measurement (TGA) was accomplished by TGA/DSC1 Mettler Toledo equipment. Thickness $(d)$ of the layer was measured using ellipsometer Mikropack SpecEL-2000-VIS at constant angle. Current $(I)$-voltage $(V)$ characteristic was obtained using electrometer Keithley 6517A in room temperature. Current-voltage measurements were performed on ITO/PAZ/conductive rubber. The PAZ solution (in chloroform) was spin-coated onto ITO covered glass substrate at room temperature. Film thickness was about $200 \mathrm{~nm}$. The area of the measured electrode was $100 \mathrm{~mm}^{2}$.

Preparation of polymer films

Films on the glass and quartz substrate were obtained by dissolving at room temperature the PAZ in chloroform to form a homogenous solution. Quantity of the 
used PAZ and chloroform was $36 \mathrm{mg}$ and $2 \mathrm{ml}$, respectively. Microscopic cover glass and quartz were situated in ultrasonic washer with deionised water for $10 \mathrm{~min}$ and then were cleaned in solution of deionised water and 2-propanol (1:1 relation), toluene, lavaged in deionised water and acetone [8].

The thin layers of the PAZ were spread by spin-coating method via drift process on the glass and quartz. To avoid contamination and defects in thin stratum this process was carried out at room temperature in atmosphere of nitrogen under atmospheric pressure. The values such as rotational speed and time of turn were set on 880 turns per minute by $10 \mathrm{~s}$.

\section{Results and discussion}

PAZ was prepared from dialdehyde and diamine via high temperature solution polycondensation in HMPA, as depicted in Fig. 1.

In our case 4,4'-diformyltriphenylamine was chosen as chromofore unit, which not only has a hole transporting property but could also reduce the rigid-rod conformation, thus improving the processibility of the material. PAZ could be dissolved in such solvents as chloroform, m-cresol, DMA or NMP. A molecular structure of the PAZ was confirmed by FTIR, proton and carbon NMR and elemental analysis and was the subject of our previous work [6] (see also "Experimental" section). In our previous paper [6] we described the spectroscopic and optical properties, mainly photoluminescence, in solution and in blend with poly(methyl methacrylate) of undoped and doped PAZs with TPA unit in the main chain. The absorption spectrum of the PAZ in chloroform solution was characterized by one well-defined band at $413 \mathrm{~nm}$ being responsible for $\pi-\pi^{*}$ transmission in the imine group. PAZ emitted blue light in chloroform solution with maximum of emission band at $480 \mathrm{~nm}$ under $400 \mathrm{~nm}$ excitation wavelength [6]. For the reason that our previous study [6] was promising we decided to investigate optical and structural properties of the PAZ with TPA unit in the main chain prepared via spincoating technique for potential used as one of the layers in organic solar cells.

A major feature of the PAZ containing TPA unit in the main chain is their complete solubility in comparison with the PAZ obtained from terephthaldicarboxaldehyde and $o$-dianisidine (abbreviated hereinafter as PAZ1, see Fig. 1). Both polymers were analyzed by thermogravimetric analysis, DSC and FTIR spectroscopy. Taking into account the chemical constitution of the PAZ and PAZ1 studied here, one may expect that they should exhibit a rather good thermal stability. The same arguments apply to their glass transition temperature $T_{\mathrm{g}}$. First we notice that, consistent with the expectations, fully conjugated PAZ and PAZ1 were thermally stable to $400{ }^{\circ} \mathrm{C}$. PAZ showed a $10 \%$ weight loss at $400{ }^{\circ} \mathrm{C}$, while a PAZ1 at $390{ }^{\circ} \mathrm{C}$. Decomposition value for both polymers at $1000{ }^{\circ} \mathrm{C}$ was about $45 \%$. Both polymers gave similar DSC properties with no melting endotherms and a clear $T_{\mathrm{g}}$. These findings clearly indicate their amorphous nature. The presence of TPA unit lead to a significant decreased in the $T_{\mathrm{g}}$ value about $80{ }^{\circ} \mathrm{C}$ (see "Experimental" section).

The FTIR spectrum of the PAZ and PAZ1 (as pellet in potassium bromide) exhibits the vibration band of the azomethine unit at $1623^{-1}$ and $1629 \mathrm{~cm}^{-1}$, 
respectively, providing further confirmation that the synthesized polymers were the PAZs. In addition to the $\mathrm{HC}=\mathrm{N}$ stretching band, a band at about $1588 \mathrm{~cm}^{-1}$ could be distinguished ascribed to $\mathrm{C}=\mathrm{C}$ stretching deformations in the aromatic ring for both materials.

In this work we investigated optical and structural properties of the PAZ layer on the glass and quartz substrate prepared by spin-coating method. Spectroscopic data discussed below clearly indicate that the substrate more or less strongly influences on the properties of the thin layer of the PAZ. We was studied this problem in greater details using FTIR, UV-vis spectroscopy and also by using X-ray Diffraction (X-ray) and Atomic Force Microscopy (AFM). Results of them are presented below.

\section{Optical measurements}

The absorption spectra of the PAZ film on the glass (abbreviated hereinafter as PAZ/Glass) and on the quartz (abbreviated hereinafter as PAZ/Quartz) substratum are shown in Fig. 2.

Independently on the kind of substratum maximum of the absorbance was observed for the PAZ/Glass and PAZ/Quartz at $405 \mathrm{~nm}$. Considering optical properties of the PAZ thin layer, useful information could be obtained about the energy band structure, characteristic of band to band transition [9-12].

$$
\alpha=\frac{1}{d} \ln \left(\frac{(1-R)^{2}}{T}\right)
$$

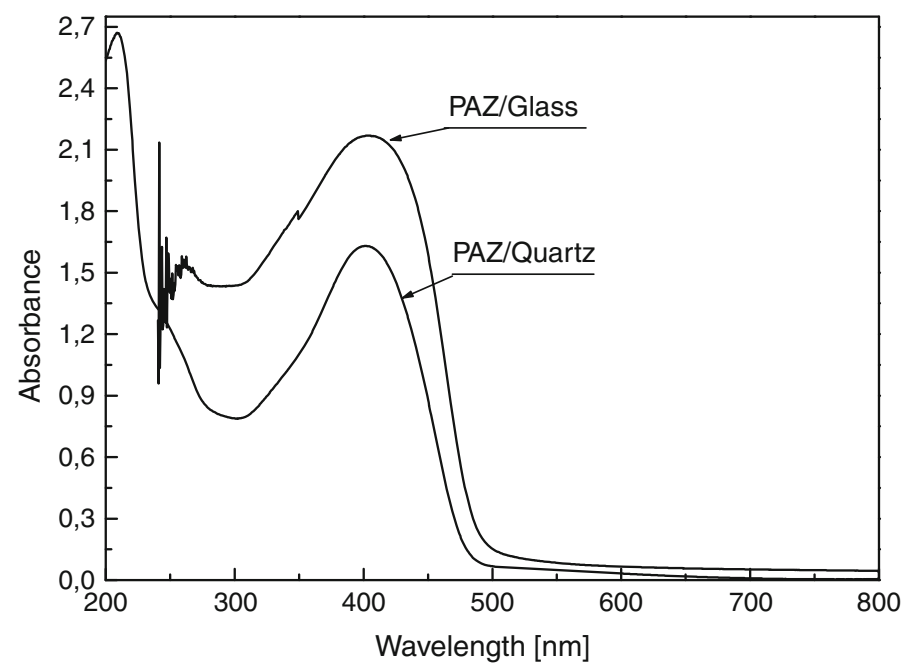

Fig. 2 Absorption spectra of the PAZ film coated on the glass and quartz 
An absorption coefficient $\alpha$ was calculated according to the Eq. 1 [9-11], where $d$ was film thickness. The typical absorption coefficient plot of the PAZ thin layer on the glass and quartz at entire energy scale from 2.0 to $6.0 \mathrm{eV}$ is illustrated in Fig. 3. On plot, an increase of the absorption coefficient $\alpha$ was observed from energy value equal to $2.5 \mathrm{eV}$.

The absorption edge of the PAZ on the glass and on the quartz was observed between 2.5 and $3.0 \mathrm{eV}$. For amorphous semiconductor materials it was possible to calculate the energy gap $E_{g}$ from Eq. 2 [7, 13, 14],

$$
\alpha \cdot E=A\left(E-E_{\mathrm{g}}\right)^{r}
$$

where $\alpha$ was absorption coefficient, $A$ was parameter independent of photon energy, $E, E_{g}$ represent photon and band gap energy, respectively. Index $r$ accepts two values $1 / 2$ or 2 connected with direct and indirect band to band transition, respectively. Type of the transition in the investigated material was determined by subscript $r=2$. What implicate that in investigated material excitation of electrons was proceeded by absorbing a photon and interaction with phonon what could be related with chemical structure of PAZ. In contrary, for PAZ1 (without TPA unit) value of index $r=1 / 2$ was admitted [11]. In our case such approach leads to Eq. 3 and that was connected with additional $\pi$ bonds which were initiated by TPA.

$$
(\alpha E)^{1 / 2}=f(E)
$$

Delimitation value of the energy gap $\left(E_{\mathrm{g}}\right)$ was determined from linear approximation of Eq. 3, as was mentioned in paper [13] for amorphous semiconductors. The absorption edge of the PAZ thin layer on the glass and quartz is shown in Fig. 4. Value of the energy gap for samples deposition on the glass and quartz was found at 2.45 .

The energy gap $\left(E_{\mathrm{g}}=2.45 \mathrm{eV}\right)$ of the PAZ film on the glass and quartz were similar. Insignificant changes into value of $E_{\mathrm{g}}$ related with amount of the solvent in

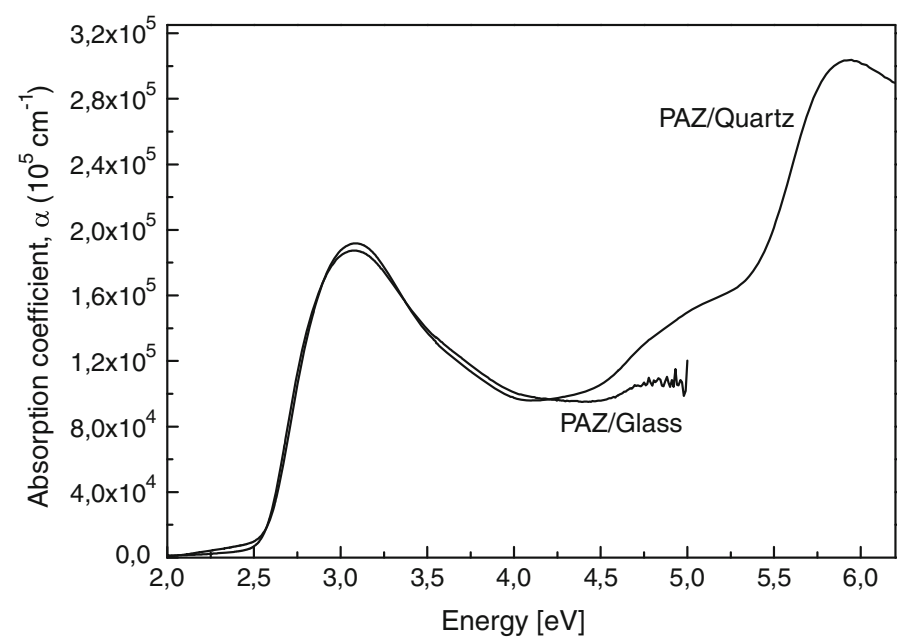

Fig. 3 Absorption coefficient of the PAZ thin layer on the glass and quartz 


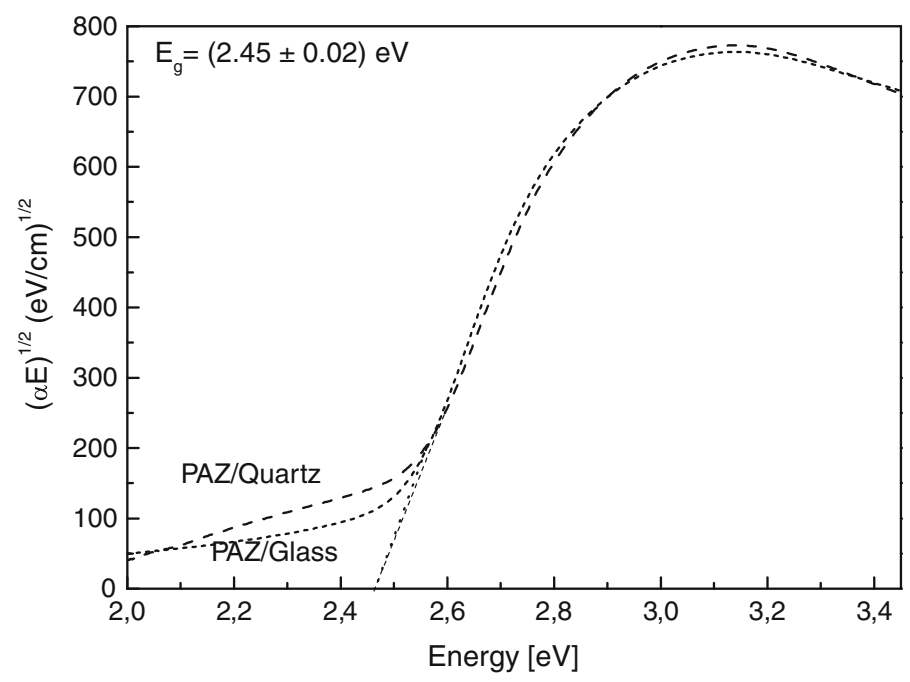

Fig. 4 Linear approximation of absorption edges of the PAZ thin layer on the glass and quartz

solution were observed. Increasing or decreasing of the band gap about $0.01 \mathrm{eV}$ was caused by different concentration of the chloroform in polymer solution.

Characteristic broad and strongest section at the absorption coefficient detected at about $3.0 \mathrm{eV}$ (Fig. 3.) was due to inter-band transition between delocalized states which were related with interaction of $\pi$-orbitals in the PAZ [15].

Measurements of the PAZ thickness layer on the glass and quartz substratum were performed with ellipsometer equipment working at constant angle. Real refraction coefficients $(n)$ of the glass, quartz and PAZ layer were required to conduct measurements. Real refraction coefficient, $n=1.42$, of the PAZ was estimated from Eq. 4, where $k$ and $R$ were imaginary refractive and reflection coefficient, respectively [16].

$$
n=\frac{1+\sqrt{R}}{1-\sqrt{R}}, \quad(k=0)
$$

Thickness of the thin PAZ layer on the glass and quartz was changing from 150 to $220 \mathrm{~nm}$ (Table 1).

Differences in thickness of the PAZ films on the glass and quartz substrate were related with used various basis. Both substrates were chemical purified by applied organic solvents. Moreover, quartz substrate was polished, and for this reason

Table 1 Thickness of the PAZ thin layer on the glass and quartz substrate

\begin{tabular}{|c|c|c|c|c|c|}
\hline \multirow{2}{*}{$\frac{\text { Code }}{\text { PAZ/Glass }}$} & \multicolumn{5}{|c|}{ Thickness of layer, $d(\mathrm{~nm})$} \\
\hline & 200 & 218 & 203 & 208 & 211 \\
\hline PAZ/Quartz & 155 & 162 & 155 & 157 & 154 \\
\hline
\end{tabular}


thickness of the thin polymer film on the quartz slide was lower (about $50 \mathrm{~nm}$ ) than on the glass one.

\section{X-ray diffraction}

The wide-angle X-ray diffraction patterns of the PAZ on the glass and quartz substratum over the $2 \theta$ range of $10^{\circ}-65^{\circ}$ are shown in Fig. 5.

PAZ was amorphous as determined by the X-ray diffraction pattern. One broad diffraction peak of diffusion type centred at $25^{\circ}$ and $30^{\circ}(2 \theta)$, respectively, for PAZ/ Glass and PAZ/Quartz was observed in plots present in Fig. 5.

Appreciable difference among the X-ray spectra of the thin PAZ layer was related with used different substratum. However, for both patterns it was allowed to conclude that investigated material had an amorphous structure what was expected and also discussed for another type of PAZs [17].

\section{AFM measurements}

The thin film morphology of the PAZ on the glass and quartz was observed by AFM technique. First we would like to say that the most common method of obtaining contact mode AFM images was the constant force method. In this method the

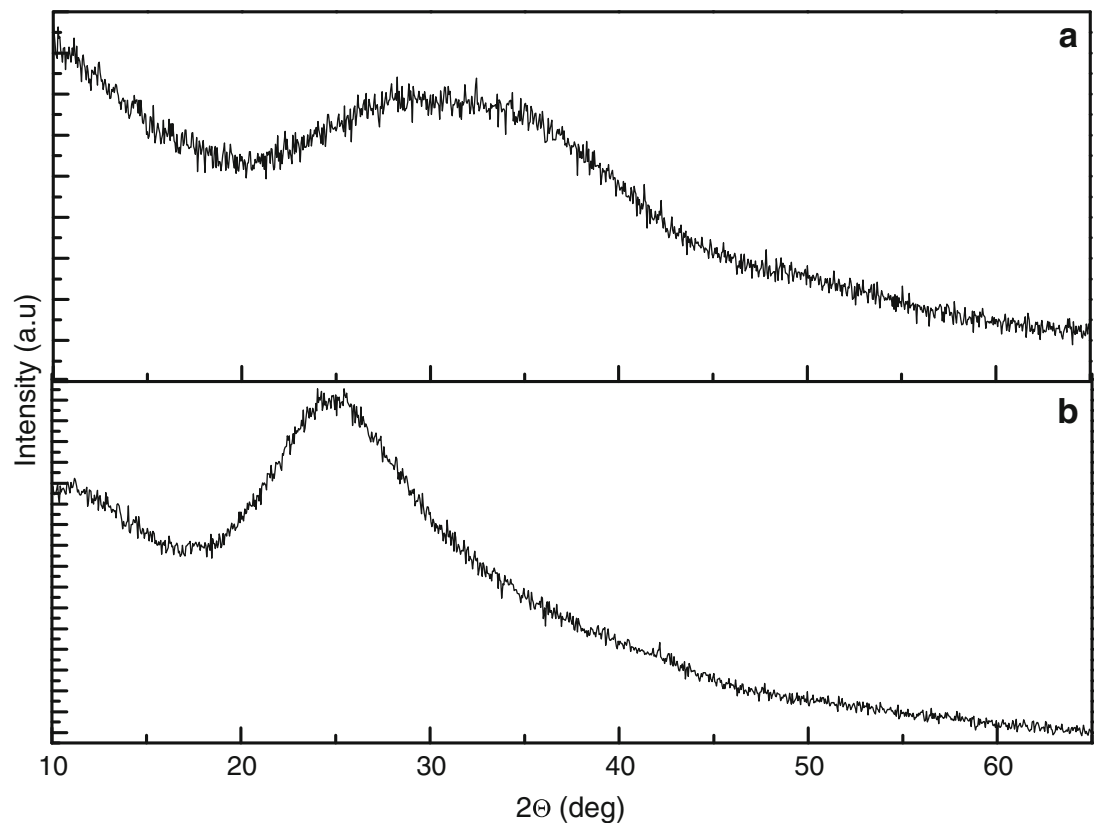

Fig. 5 X-ray diffractograms intensity versus Bragg angle graph of polyazomethine thin layer on glass $(a)$ and quartz $(b)$ substratum 
Fig. 6 AFM images of the a PAZ/Glass and b PAZ/Quartz (surface pattern $5 \times 5 \mu^{2}$ )
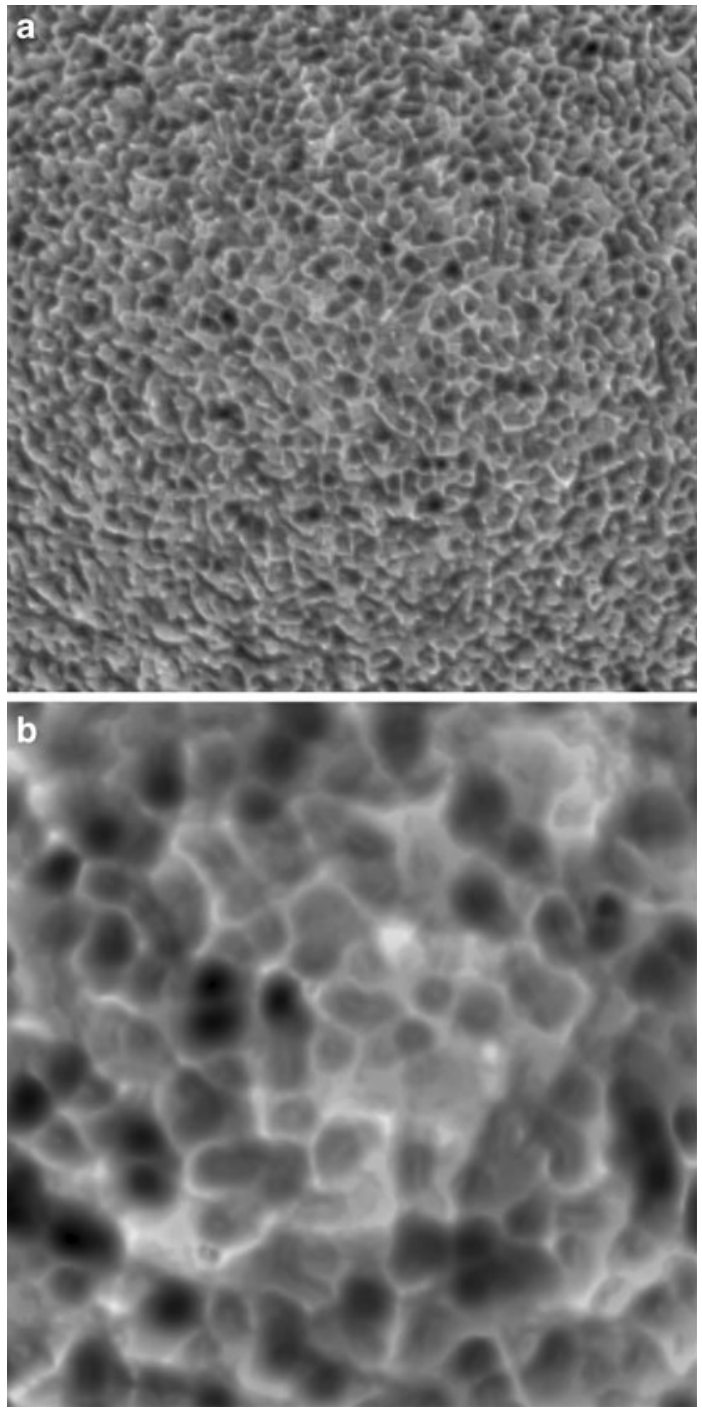

correction voltage for $z$-piezo restoring the cantilever to its original deflection was used as the $z$-data for imaging the sample surface topography (constant force or topography image). The results of surface topography presented here were obtained in the "constant force" mode. Practically, however, the load force varies during surface scanning and the cantilever deflection photo-sensor output so called "error signal" was used to acquire error signal image simultaneously with topographical imaging. The error signal images, although containing no true height information, could give additional, complementary information about thin film surface appearance and may resemble the micrographs observed in SEM or TEM images of replicated sample surfaces. Images of the PAZ on the glass and quartz are presented in Fig. 6. 


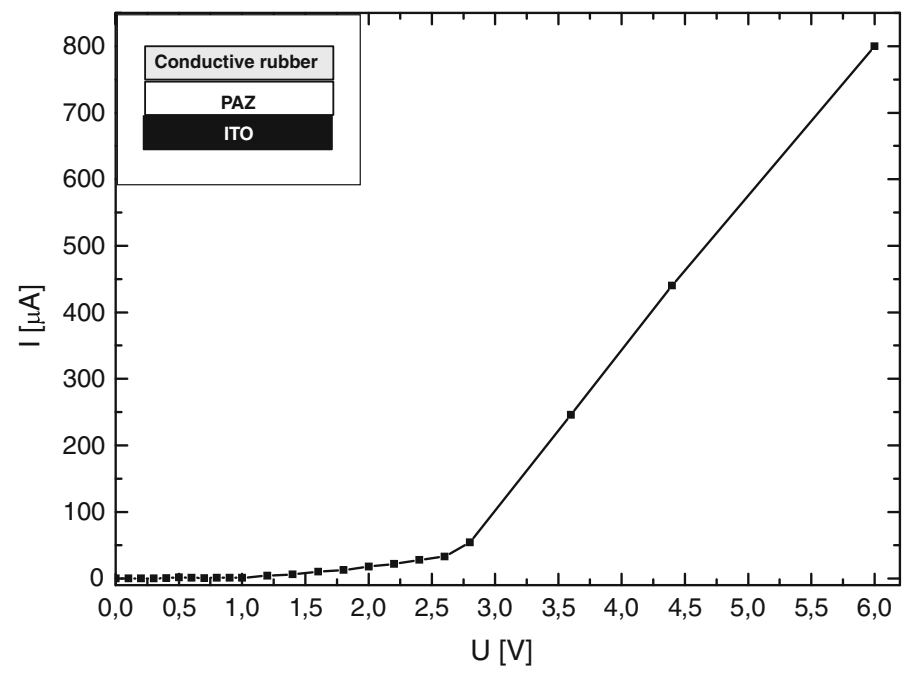

Fig. 7 Current-voltage characteristic of the device ITO/PAZ/conductive rubber

The thin films of the PAZ on the glass (Fig. 6a) and quartz (Fig. 6b) presented a homogenous and smooth surface. Characteristic granulation was typical for the polymer thin layers. Moreover, agglomerates are visible in thin films of PAZ (Fig. 6). Scale of the granulated polymers concentration was related with a porosity of the substratum.

\section{Current-voltage measurements}

Semiconductor behaviour of the PAZ was characterized by preliminary electrical measurements in room temperature. Current-Voltage characteristic of ITO/PAZ/ conductive rubber device was shown in Fig. 7.

From obtained plot, it was possible to conclude that increasing voltage extort fast extension of current above $3 \mathrm{~V}$. Value of conductivity of PAZ was in the range $10^{-8}-10^{-7} \mathrm{~S} / \mathrm{m}$, what categorized PAZ between semiconductors and dielectrics (high band gap organic semiconductors). Further investigations are in progress.

\section{Conclusion}

Spin-coating method appeared to be an effective tool to prepared good quality of the PAZ thin layer. The technological parameters influenced on the energy gap, thickness and surface structure of the investigated PAZ. Presented results seem to be helpful to better understanding the opto(electrical) properties of that PAZ. It could be concluded that the investigated PAZ is an amorphous semiconductor with the wide energy gap. Therefore, such PAZ with the TPA in the main chain could be potentially used to produce photovoltaic devices. 
Acknowledgements The authors thank Dr. hab. eng. W. Mielcarek for X-ray measurements and Dr. eng. A. Sikora for facilities of equipment to do a current-voltage measurement. This work was financial supported in the frame of expenditure on science (2010-2011) No. N N510191538.

Open Access This article is distributed under the terms of the Creative Commons Attribution Noncommercial License which permits any noncommercial use, distribution, and reproduction in any medium, provided the original author(s) and source are credited.

\section{References}

1. Sun S, Sariciftci NS (2005) Organic photovoltaics: mechanisms, materials and devices. CRC Press, Boca Raton, FL

2. Conibeer G (2007) Third-generation photovoltaics. Mater Today 10:42-50

3. Tang CW (1986) Two-layer organic photovoltaic cell. Appl Phys Lett 48:183-185

4. Iwan A, Sek D (2008) Processible polyazomethines and polyketanils: from aerospace to lightemitting diodes and other advanced applications. Prog Polym Sci 33:289-345

5. Mishra A, Fischer MKR, Bauerle P (2009) Metal-free organic dyes for dye-sensitized solar cells: from structure property relationships to design rules. Angew Chem Int Ed 48:2474-2499

6. Sek D, Iwan A, Jarzabek B, Kaczmarczyk B, Kasperczyk J, Mazurak Z, Domanski M, Karon K, Lapkowski M (2008) Hole transport triphenylamine-azomethine conjugated system: synthesis and optical, photoluminescence, and electrochemical properties. Macromolecules 41:6653-6663

7. Meng F, Liu Ch, Hua J, Cao Y, Chen K, Tian H (2003) Novel linear and tri-branched copolymers based on triphenylamine for non-doping emitting materials. Eur Polym J 39:1325-1331

8. Mikroyannidis JA, Spiliopoulos IK, Kulkarni AP, Jenekhe SA (2004) Synthesis and optical properties of poly ( $p$-phenylenevinylene)s bearing tetraphenylthiophene or dibenzothiophene moieties along the main chain. Synth Met 142:113-120

9. Palewicz M, Iwan A, Doskocz J, Strek W, Sek D (2009) Optical properties of thin films of polyazomethine with triphenylamine unit in the main chain prepared by spin-coating method. In: Schwarz $\mathrm{H}$, Leonowicz Z (ed) The eight international conference on environment and electrical engineering, Karpacz, Poland, pp 179-182

10. Luca D, Hsu LS (2003) Structural evolution and optical properties of $\mathrm{TiO}_{2}$ thin films prepared by thermal oxidation of PLD Ti films. J Optoelectron Adv Mater 5:835-840

11. Rusu GI, Airinei A, Rusu M, Prepelit P, Marin L, Cozan V, Rusu II (2007) On the electronic transport mechanism in thin films of some new poly(azomethine sulfone)s. Acta Mater 55:433-442

12. Bauer G, Richter W (eds) (1996) Optical characterization of epitaxial semiconductor layers. Springer, Berlin

13. Jarzabek B, Weszka J, Domanski M, Jurusik J, Cisowski J (2006) Optical properties of amorphous polyazomethine thin films. J Non-Cryst Solids 352:1660-1662

14. Seeger K (1999) Semiconductor physics. Springer, Berlin, Heidelberg, New York

15. Bourgeaux M, Skene WG (2007) A highly conjugated $p$ - and $n$-type polythiophenoazomethine: synthesis, spectroscopic, and electrochemical investigation. Macromolecules 40:1792-1795

16. Jarzabek B, Weszka J, Burinan A, Pocztowski G (1996) Optical properties of amorphous thin films of the Zn-P system. Thin Solid Films 279:204-208

17. Jarzabek B, Weszka J, Domanski M, Jurusik J, Cisowski J (2008) Optical studies of aromatic polyazomethine thin films. J Non-Cryst Solids 354:856-862 